\title{
Rare nature of mushroom poisoning means drug trials rarer still
}

A recent case of mushroom poisoning has highlighted the difficulties of investigating treatments for a rare illness.

In late December, a woman and her two grandsons in California ate soup made from deadly Amanita phalloides mushrooms they had picked. These so called 'death cap' mushrooms contain amatoxin-a potentially fatal peptide molecule that inhibits the enzyme RNA polymerase in liver cells.

Todd Mitchell of the Santa Cruz, Californiabased Dominican Hospital persuaded the US Food and Drug Administration (FDA) to approve an emergency investigational new drug (IND) application, which allowed a drug called silibinin to be successfully administered to the three individuals.

Vials of the drug were obtained despite the fact that the European offices of the company that makes silibinin were closed for Christmas break. "We were fortunate to get the currier onto a booked-up flight by upgrading their ticket," says Mitchell.

The case closely mirrors a January 2007 poisoning in which a grandmother died after eating a meal prepared with the same variety of Amanita. Although her daughter, son-inlaw and three grandchildren had joined her for dinner, they survived the incident after receiving silibinin obtained by Mitchell.

"One of the 2007 patients was among the sickest I have ever seen," says Kent Olson, the medical director for the San Francisco division of the California Poison Control System. "If the silibinin had come much later it may have been too late. When other patients have gotten that sick, they have either died or ended up needing a liver transplant."

Marketed as Legalon-Sil by the pharmaceutical company Madaus in Cologne, Germany, the milk thistle extract silibinin has been used to treat only 400 cases in Europe since it was approved in 1984. After it first hit the market in Germany, other European countries followed suit. Yet much of the data in support of silibinin is anecdotal, and some US doctors say more clinical research is needed into the drug's efficacy.

Only about 50 cases of amatoxin poisoning are reported in the US each year, which is too few for a large-scale, randomized trial, and it's unethical to deny patients comprehensive treatment. Moreover, when good general care is offered, amatoxin mortality rates vary between $5 \%$ and $15 \%$. "This means we can't say for sure that [silibinin] has any affect," says Olsen.

Silibinin has yet to be directly compared to general assistive treatments such as penicillin and activated charcoal-a slurry drink thought to help absorb toxin in the body. When administered intravenously, silibinin is thought to prevent toxins from accumulating in liver cells, but Joe Veilleux, who heads a US subsidiary of Madaus, explains there is some uncertainty over the purified extract's mechanism of action.

Despite these unanswered questions, silibinin is widely viewed as safe. "There is no way to know if patients would live anyway, even without it, but there is certainly no harm with using silibinin," says Marilyn Shaw, who also serves as a mushroom poisoning consultant to the Rocky Mountain Poison and Drug Center.

The narrow market for silibinin in the US probably reduces incentives for Madaus to push for orphan drug status.

Mitchell, meanwhile, hopes the FDA will grant an open IND and allow US doctors to keep stock supplies of silibinin on hand,

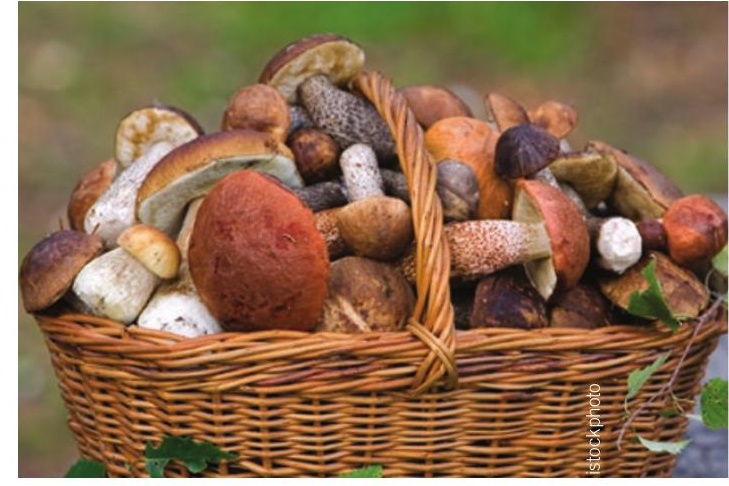

Mushrooming problem: Treating rare poisonings

although the FDA has opted against this in the past. In the absence of such approval, the drug cannot be stored in the US, and doctors must apply for an emergency IND on a caseby-case basis.

Amy Coombs, San Francisco

\section{Independent working group puts genetic tests under the microscope}

An independent working group established by the US Centers for Disease Control and Prevention $(C D C)$ to evaluate the validity of genetic testing in clinical practice released a new set of recommendations in late January. The experts reached a consensus that more research is needed to know whether genetic tests can reliably guide medical treatment.

"The big message from these recommendations is that there is a lot more work that needs to come from the research community in terms of what genetic tests really, physically mean," says Joan Scott, a member of the working group and deputy director of the Washington, DC-based Genetics and Public Policy Center at John Hopkins University. "Right now, patients need to be taken on a case-by-case basis. Genetic tests can offer a piece of information, but they shouldn't be used to make decisions."

The working group reviewed several new approaches: profiling of tumor gene activity to guide breast cancer treatment, genotyping of individuals with metastatic colorectal cancer to steer dosage of the chemotherapy agent irinotecan and testing of strategies associated with Lynch
Syndrome, a condition that can raise the risk of certain cancers (Genet. Med. 11, 63-73; 2009; Genet. Med. 11, 15-20; 2009; Genet. Med. 11 35-41;2009).

These add to the only previous recommendation issued thus far-a 2007 review of tests to predict effects of a treatment for depression (Genet. Med. 9, 819-825; 2007).

Scott said that these tests were chosen for observation in part because they are representative of the most studied genetic tests currently used in a clinical, nonpediatric and nonreproductive setting.

Three of these recommendations stem from observations of how clinicians have used genetic testing to determine the course of treatment for a disease. In each case, the group could not recommend for or against use of the testing for this purpose, because there were substantial knowledge gaps in the relation of the genetic test to the disease.

That said, in the case of Lynch Syndrome, the group found that identification of certain genetic markers did indicate that relatives of the affected individual should also be tested to identify potential early onset of the disease. Stu Hutson, Gainesville, Florida 